\title{
TARHATUN MINKIN (MUSTELA VISON) CO ja CO- LOPETUS
}

\author{
Hannu T. Korhonen ${ }^{1}$, Pekka Eskeli ${ }^{1}$, Juhani Sepponen ${ }^{1}$, Sigitas Cizinauskas ${ }^{2}$ ja Janis Jesernics ${ }^{2}$ \\ ${ }^{1}$ MTT Kotieläintutkimus, Silmäjärventie 2, 69100 Kannus; etunimi.sukunimi@mtt.fi \\ ${ }^{2}$ Animal neurology Clinic AISTI, Virtatie 9,01600Vantaa; etunimi.sukunimi@aisti.info
}

\section{Tiivistelmä}

Eläinten lopetukseen on kiinnitettävä erityistä huomiota jottei niille aiheuteta turhaa kärsimystä. Selkeänä tavoitteena tulee pitää sitä, että lopetus on mahdollisimman nopea ja kivuton. Eläinten hyvinvointi tulee taata kaikissa olosuhteissa.

Tarhatun minkin lopetukseen on menneinä vuosikymmeninä kokeiltu useita menetelmiä. Tällaisia ovat olleet muun muassa niskan murtaminen, sähköllä lopetus, hiilimonoksidi (CO), hiilidioksidi $\left(\mathrm{CO}_{2}\right)$, typpi $\left(\mathrm{N}_{2}\right)$ ja erilaiset injektiot. Näistä niskan murtaminen on nykyisin kielletty. Sähköllä lopettamista on kokeiltu jossain määrin, mutta se ei ole nykykäytäntöön kovin soveltuva menetelmä eikä siksi varsinaisesti käytössä. Lisäksi se edellyttäisi vielä lisävarmistuksena esimerkiksi niskan murtamista. Tällä hetkellä vallitseva menetelmä on hiilimonoksidi (CO), jota käytetään yleisesti minkkitarhoilla. Käytetty kaasu on peräisin joko koneesta tai pullosta.

Tämän tutkimuksen tavoitteena oli selvittää minkkien koneellisella (epäpuhtaalla) hiilimonoksidilla (CO) sekä pullotetulla (puhtaalla) hiilimonoksidilla (CO) ja hiilidioksidilla $\left(\mathrm{CO}_{2}\right)$ tapahtuvaa lopetusta. Tarkoituksena oli saada yksityiskohtaista, tarkennettua tietoa lopetusmenetelmästä, menetelmän toimivuudesta ja seurattavista muuttujista. Hanke tähtää lainsäädännön kehittämiseen. Tietoa tullaan käyttämään erityisesti uuden MMM:n lopetusasetuksen käytäntöön saattamisessa. Tulosten pohjalta laaditaan toimintaohjeisto lopetuksen eettisyyden varmistamiseksi. Tutkimusmenetelminä ovat kyselytutkimus ja elektrofysiologinen koe.

Kyselytutkimus osoitti, että Hollannissa minkin lopetukseen käytetään ainoastaan pullotettua CO:ta. Suomessa ko. menetelmä ei ole käytössä vaan minkit lopetetaan joko koneellisella CO:lla (ruokintatrukki, muu moottori) tai pullotetulla $\mathrm{CO}_{2}$ :lla. Koneellinen $\mathrm{CO}$ on selvästi yleisempi (75.3\% turkistiloista käyttää). Pullotetun $\mathrm{CO}_{2}$ käyttö on lisääntymässä maassamme. Kaikki kolme menetelmää näyttävät toimivan melko hyvin. Ne on sopeutettu kunkin maan olosuhteisiin ja tarpeisiin. Tarhaajat eivät ole kokeneet suurempia terveydellisiä ongelmia kaasujen käytöstä.

Elektrofysiologisessa kokeessa neljä ryhmää dark urosminkkejä $(\mathrm{N}=35)$ testattiin seuraavasti: lopetus pakokaasulla ( $\mathrm{CO} \geq 4 \%$ pitoisuus), lopetus hiilidioksidilla $\left(\mathrm{CO}_{2}\right.$ pullosta, $\geq 80 \%$ pitoisuus), lopetus hiilimonoksidilla (CO pullosta, $\geq 4 \%$ ja $\geq 2 \%$ pitoisuus). Aivorungon aktiivisuus (BAER), aivosähkökäyrä (EEG), sydänkäyrä (ECG) sekä hengitystiheys mitattiin ennen ja lopetuksen aikana. Tulokset osoittavat, että tutkitut kaasut vaikuttavat ensin aivoihin ja aivonrungon aktiviteettiin mikä näkyy EEG:n ja BAER:n katoamisena. Koska herkkyys kivulle on erityisesti suhteessa tietoisuuteen ja aivojen toimintaan, niin voidaan katsoa niiden tehokkaasti ja ensisijaisesti johtavan kivuttomaan tilaan. $\mathrm{CO}$ ja $\mathrm{CO}_{2}$ soveltuvat minkin lopetukseen.

Asiasanat: Eläinten hyvinvointi; Turkiseläimet; Eettinen lopetus; Kyselytutkimus, Elektrofysiologia 


\section{Johdanto}

Eläinten lopettaminen voi aiheuttaa kipua, stressiä, pelkoa ja muuta häiriötä siitäkin huolimatta että käytettävissä oleva lopetusmenetelmä on paras mahdollinen mikä tällä hetkellä tunnetaan. Tämän vuoksi eläinten lopetukseen on kiinnittävä erityistä huomiota jottei niille aiheuteta turhaa kärsimystä (Council of the European Union 2009, EFBA 2009). Selkeänä tavoitteena tulee pitää sitä, että lopetus on mahdollisimman nopea ja kivuton. Lopetusta suorittavan henkilökunnan tulee olla asiantuntevaa ja riittävästi koulutettua sekä hyvin motivoitunutta, jotta lopetuksen eettiset reunaehdot varmasti toteutuvat. Eläinten hyvinvointi tulee taata kaikissa olosuhteissa.

Tarhattujen turkiseläinten hyvinvointiin on kiinnitetty runsaastí huomiota viime vuosikymmeninä (Nimon \& Broom 1999, Spruijt, 1999, Hovland \& Bakken 2000). Eläinten tuotantoympäristön ja kasvatusolosuhteiden parantaminen on ollut keskeinen tutkimuskohde. Tällä hetkellä tutkimuksen painopistettä ollaan siirtämässä lopetusmenetelmien kehittämiseen ja eettisyyteen. Tästä hyvänä esimerkkinä on kattava tutkimus, jossa selvitettiin tarhattujen sinikettujen (Alopex lagopus) lopetuksen toimivuus ja eettiset reunaehdot (Korhonen ym. 2009).

Tarhattujen minkkien (Mustela vison) lopetukseen on menneinä vuosikymmeniä kokeiltu useitakin menetelmiä. Tällaisia ovat olleet mm. niskan murtaminen, sähköllä lopetus, hiilimonoksidi (CO), hiilidioksidi $\left(\mathrm{CO}_{2}\right)$, typpi $\left(\mathrm{N}_{2}\right)$ ja erilaiset injektiot (Loftsgard ym. 1972, Gierløff 1980, Löliger 1984, Lamboy ym. 1985, Enggaard Hansen ym. 1991). Näistä niskan murtaminen on nykyisin kielletty. Sähköllä lopettamista on kokeiltu jossain määrin, mutta se ei ole nykykäytäntöön kovin hyvin soveltuva menetelmä eikä siksi varsinaisesti käytössä. Lisäksi se edellyttäisi vielä lisävarmistuksena niskan murtamista. Tällä hetkellä vallitseva menetelmä turkistiloilla on hiilimonoksidi, jota käytetään yleisesti Euroopassa. Käytetty hiilimonoksidi on peräisin joko koneesta tai pullosta. Pullotetun hiilimonoksidin käyttö on tosin melko vähäistä tällä hetkellä. European Fur Breeders' Association'in (EFBA) tilastojen mukaan sitä käytetään lähinnä Hollannissa ja Ranskassa.

EU:ssa valmisteilla ollut lopetusasetus (Council of the European Union, 2009) on nyt olemassa ja sitä ryhdytään soveltamaan käytäntöön meillä Suomessa vuoden 2013 alusta. Asetuksessa edellytetään, että lopetukseen käytettävän kaasun laatua seurataan. Kaasun tulee olla sopivasti viilennettyä, riittävästi suodatettua ja vapaata ärsyttävistä komponenteista. Eläimiä tulee pystyä tarkkailemaan koko lopetuksen ajan. Eläimet tulee laittaa lopetuslaitteeseen yksitellen. Eläintä ei myöskään saa laittaa kammioon ennen kuin minimikonsentraatio CO:ta on saavutettu. Tutkittua tietoa asiasta siis tarvitaan, jotta käytännöt saataisiin selkeiksi. Myös turkiselinkeinon kannalta lopetuksen toimivuus ja läpinäkyvyys on etu.

Tämän tutkimuksen tavoitteena on selvittää minkkien puhtaalla (pullotettu) ja epäpuhtaalla hiilimonoksidilla (koneellinen, bensiinikäyttöinen) ja puhtaalla $\mathrm{CO}_{2}$ tapahtuvaa lopetusta. Tarkoituksena on saada yksityiskohtaista, tarkennettua tietoa lopetusmenetelmästä, menetelmän toimivuudesta ja seurattavista muuttujista. Hanke tähtää lainsäädännön kehittämiseen. Tietoa tullaan käyttämään erityisesti uuden MMM:n lopetusasetuksen käytäntöön saattamisessa. Tulosten pohjalta laaditaan toimintaohjeisto lopetuksen eettisyyden varmistamiseksi.

\section{Aineisto ja menetelmät}

Tämä Maataloustieteen Päivillä 2012 posterina esitettävä tutkimus on osa suurempaa tutkimushanketta (Tarhatun minkin (Mustela vison) $\mathrm{CO}$ ja $\mathrm{CO}_{2}$-lopetus: lainsäädännöllinen näkökulma) joka pitää sisällään seuraavat osakokonaisuudet:(1) Lopetuksen nykymenetelmät ja tilanne turkistiloilla; kyselytutkimus Suomessa ja Hollannissa (vv. 2010-2011), (2) Epäpuhtaan hiilimonoksidilaitteiston toimivuus (vv. 20102011), (3) Lopetusmenetelmän tehokkuus; elektrofysiologinen koe laboratoriossa (vv. 2010-2011), (4) Toimintaohjeisto lopetuksesta ja koulutus (vv. 2012-13). Tutkimuksen pääpaikkana on MTT Kotieläintutkimus, Alueet, Silmäjärventie 2, 69100 Kannus. Tutkimusta on lisäksi tukenut Kannuksen Tutkimustila Luova Oy. Erityiskiitokset tutkimusmestari Pekka Toikkaselle. Hankkeen rahoittajina ovat Maa- 
ja metsätalousministeriö (MMM), European Fur Breeders’ Association ( EFBA) ja Maa- ja elintarvitalouden tutkimuskeskus (MTT).

Kyselytutkimuslomake toimitettiin suomalaisille turkiseläintuottajille elo-syyskuussa 2010 ja hollantilaisille vastaavasti lokakuussa 2010. Suomessa kyselylomake lähetettiin 397 turkistilalle, vastausprosentti oli 34.3\%. Hollannissa lähettiin 143 turkistilalle, vastausprosentti oli 24.5\%. Aineisto tallennettiin ja analysoitiin MTT:1lä Kannuksessa (SAS 9.1 release).

Elektrofysiologisessa kokeessa neljä ryhmää standard dark urosminkkejä testattiin seuraavasti: lopetus pakokaasulla ( $\mathrm{CO} \geq 4 \%$ (8 eläintä), lopetus hiilidioksidilla $\left(\mathrm{CO}_{2}\right.$ pullosta, 99.5\% pitoisuus, 8 eläintä), hiilimonoksidi (CO pullosta, 4\% taso, 9 eläintä) ja lopetus hiilimonoksidilla (CO pullosta, 2\% taso, 6 eläintä). Aivorungon aktiivisuus (Brainstem auditory evoked responses, BAER), aivosähkökäyrä (EEG), sydänkäyrä (ECG) sekä hengitystiheys mitattiin ennen ja eutanasian aikana. Näiden muuttujien avulla selvitettiin kuinka nopeasti eläin kuolee ja kuinka eettinen lopetusmenetelmä on. Tilastoanalyysit tehtiin Kruskal-Wallis ANOVA:1la.

\section{Tulokset ja tulosten tarkastelu}

Kyselytutkimus osoitti, että Hollannissa tarhat ovat selvästi keskimäärin suurempia kuin Suomessa. Hollannissa minkin lopetukseen käytetään ainoastaan pullotettua CO:ta. Suomessa ko. menetelmä ei ole käytössä vaan minkit lopetetaan joko koneellisella CO:lla (ruokintatrukki, muu moottori) tai pullotetulla $\mathrm{CO}_{2}$ :1la. Koneellinen $\mathrm{CO}$ on selvästi yleisempi (75.3\% turkistiloista käyttää). Pullotetun $\mathrm{CO}_{2}$ käyttö on lisääntymässä maassamme. Kaikki kolme menetelmää näyttävät toimivan melko hyvin. Ne on sopeutettu kummankin maan olosuhteisiin ja tarpeisiin. Tarhaajat eivät ole kokeneet suurempia terveydellisiä ongelmia kaasujen käytöstä. Lopetuslaatikon koko kummassakin maassa on suunnilleen samansuuruinen eli 0.68-0.72 $\mathrm{m}^{3}$. Eläinten kuolema laatikossa arvioidaan käyttöajan perusteella sekä kuuntelemalla kuuluuko laatikosta ääniä tai liikettä.

Hiilidioksidia on käytetty sen hyvien tainnutusominaisuuksien, suhteellisen turvallisen käsiteltävyyden ja edullisen saatavuuden vuoksi monien eläinlajien lopetuksessa. Hiilidioksidin hengittäminen saa aikaan hapen puutteen sekä hiilidioksidin kertymisen vereen. Hiilidioksidimyrkytys syntyy, kun kaasujen vaihto hengitystapahtuman yhteydessä on riittämätöntä. Tällöin hiilidioksidi kertyy elimistöön. Seurauksena ovat erilaiset myrkytysoireet, jotka alkavat keskushermostosta. Hermoimpulssien välitys aivokuoreen häiriintyy ja eläin taintuu. Oireet alkavat hengityksen kiihtymisestä.

Hiilimonoksidi (CO) eli häkä on väritöntä, hajutonta ja ärsyttämätöntä ja hieman ilmaa kevyempää kaasua. Hiilimonoksidi imeytyy keuhkojen kautta. Elimistöön pääsevän CO:n määrä riippuu hengitetyn ilman tilavuudesta, ilman CO-pitoisuudesta ja altistuksen kestosta. CO yhtyy hemoglobiiniin, jolloin muodostuu karboksihemoglobiinia (COHb), joka ei kuljeta happea. CO:lla on noin 220 kertaa niin suuri affiniteetti hemoglobiiniin kuin hapella. Plasmaan liuenneen ja kudosten häkäpitoisuuden merkitys voi olla suuri. CO:n toksisuus perustuu kudosten hapenpuutteeseen ja CO:n suoraan aiheuttamiin kudosvaurioihin. Erityisen herkkiä kudoksia ovat keskushermosto ja sydän.

Elektrofysiologinen koe laboratoriossa osoitti, että keskimääräinen aika jolloin BAER väheni/katosi oli 112/176, 138/183, 235/390 ja 528/833 sekuntia kaasutuksen alkamisesta eri ryhmissä. Keskimääräinen aika jolloin EEG muuttui/katosi oli 42/86, 39/75, 55/190 ja 176/426 sekuntia. Keskimääräinen aika ensimmäisiin muutoksiin/katoamiseen hengityksen osalta oli 42/217, 28/227, 144/477 ja 331/901 sekuntia. Keskimääräinen aika muutoksiin/katoamiseen ECG:n osalta oli 105/292, 117/220, 215/289 ja 481/682 sekunttia kaasutuksen alusta. Tulokset indikoivat että tutkitut kaasut vaikuttavat ensin aivoihin ja aivonrungon aktiviteettiin mikä näkyy EEG:n ja BAER:n katoamisena. Koska herkkyys kivulle on erityisesti suhteessa tietoisuuteen ja aivojen toimintaan, niin voidaan katsoa niiden tehokkaasti ja ensisijaisesti johtavan kivuttomaan tilaan.

Eläinten lopettaminen voi aiheuttaa kipua, stressiä, pelkoa ja muuta häiriötä siitäkin huolimatta että käytettävissä oleva lopetusmenetelmä on tällä hetkellä tunnetuista paras mahdollinen. Tämän vuoksi eläinten lopetukseen on kiinnitettävä erityistä huomiota jottei niille aiheuteta turhaa kärsimystä. Selkeänä tavoitteena tulee pitää sitä, että lopetus on mahdollisimman nopea ja kivuton. Lopetusta suorittavan henkilökunnan tulee 
olla asiantuntevaa ja riittävästi koulutettua sekä hyvin motivoitunutta, jotta lopetuksen eettiset reunaehdot varmasti toteutuvat. Eläinten hyvinvointi tulee taata kaikissa olosuhteissa. Tutkimuksessa käytetyt lopetusmenetelmät näyttävät soveltuvan hyvin minkin tehokkaaseen ja eettiseen lopetukseen. Kaikki eläimiä käsittelevät tahot ovat vastuussa niiden hyvinvoinnista ja oikeasta kohtelusta. Hyvän käytännön toimintaohjeisto minkkien lopetuksesta turkistiloilla on paikallaan. Se tullaan laatimaan ennen kuin uusi lopetusasetus otetaan turkistiloilla käyttöön v. 2013.

\section{Johtopäätökset}

Kyselytutkimuksen mukaan kaikki kolme käytössä olevaa lopetusmenetelmää näyttävät toimivan hyvin. Tarhaajien mukaan niistä ei ole aiheutunut myöskään ongelmia kaasujen käyttäjille. Elektrofysiologinen koe osoitti, että kaasut vaikuttavat minkillä ensin aivoihin ja aivorunkoon, mikä johtaa nopeasti tietoisuuden katoamiseen. Näin myöskään minkki ei koe kipua eikä stressiä. Riittävä eläinten hyvinvointi voidaan taata käytettävissä olevilla menetelmillä. Tulokset ovat käytäntöön sovellettavissa. Hyvän toimintatavan ohjeisto lopetuksesta tullaan laatimaan.

\section{Kirjallisuus}

Asetukset. 2009. Neuvoston Asetus (EY) n:o 1099/2009, annettu 24 päivänä syyskuuta, eläinten suojelusta lopetuksen yhteydessä. MMM.

Council of the European Union. 2009. Proposal for Council Regulation on the protection of animals at the time of killing. Council of the European Union, Brussels, 16 June 2009. Interinstitutional file: 2008/0180 (CNS).

EFBA. 2009. EFBA,s response to the Revision of Council Directive 93/119/EC on the protecvtion of animals at the time of slaughter or killing. November 2008, Bruxelles. Belgique, 9 s.

Enggaard Hansen,N., Creutzberg, A. \& Simonsen, H.B. 1991. Euthanasia of mink (Mustela vison) by means of carbon dioxide $\left(\mathrm{CO}_{2}\right)$, carbon monoxide $(\mathrm{CO})$ and nitrogen $\left(\mathrm{N}_{2}\right)$. Br. vet. J. 147(2):140-146.

Gierløff, B.C.H. 1980. Humane euthanasia of Danish Pelter mink with Thiopentone in contrast to killing with Chloral-hydrate. Dansk Vet. Tidskr. 63.23.

Hovland, A-H. \& Bakken, M. 2000. The welfare situation of farmed foxes in relation to domestication status and compared to other farmed species. Agric. Univ. of Norway (NLH), Dept. of Anim. Sci. 88 sivua.

Korhonen, H.T., Cizinauskas, S. \& Viitmaa, R. 2009. Evaluation of the traditional way of euthanasia of farmed foxes from an animal welfare point of view. Ann. Anim. Sci. 9(1):73-87.

Lamboy, E., Roelofs, J.A. \& van Voorst, N. 1985. Euthanasia of mink with carbon monoxide. Veterinary Record 116: 416.

Loftsgard, G., Braathen, S. \& Helgebostad, A. 1972. Electrical stunning of mink. Vet. Rec. 91: 132-134. Löliger,H. Ch. 1984. The euthanasia of fur bearing animals for pelting. Teoksessa: Proceedings of the $3^{\text {rd }}$ International Scientific Congress on Fur Animal Production. Versialles , France. Communication no. 54.

Nimon AJ, Broom DM. 1999. The welfare of farmed mink (Mustela vison) in relation to housing and management: a review. Anim Welfare 8: 205-228.

Spruijt, B.M. 1999. The welfare situation of farmed mink as compared to other farmed animals and the question of domestication of farmed mink. Animal Welfare Centre, Veterinary Faculty, Utrecht University, The Netherlands. $65 \mathrm{~s}$. 